\title{
LUGARES DE MEMÓRIA DA DITADURA E A PATRIMONIALIZAÇÃO DA EXPERIÊNCIA POLÍTICA
}

\author{
Icléia Thiesen' \\ Universidade Federal do Estado do Rio de Janeiro \\ Priscila Cabral Almeida ${ }^{2}$ \\ Universidade Federal do Estado do Rio de Janeiro
}

\section{RESUMO:}

Lugares de memória vêm se institucionalizando em espaços outrora utilizados por instituições públicas cujas atividades foram marcadas pela violência e sobretudo pelo segredo em torno do seu cotidiano. Na região do Bico do Papagaio, na cidade de Marabá (PA), está situada a Casa Azul, onde funcionou o DNER nas décadas de 1970 e 1980 , encobrindo suas reais funções, pois constituía, na prática, um centro clandestino de tortura. Em Xambioá, norte de Goiás, hoje Tocantins, houve diversos combates no mesmo período. Este artigo tem por objetivo analisar acontecimentos ocorridos no âmbito do episódio conhecido por Guerrilha do Araguaia. Trata-se de uma estratégia da memória voltada para a apropriação, patrimonialização e musealização desses espaços, dando publicidade aos fatos encobertos pela zona cinzenta da violência de Estado perpetrada durante a Ditadura de 1964

\section{PALAVRAS-CHAVE:}

patrimônio; lugares de memória; Casa Azul; GuerriIha do Araguaia; justiça de transição.

\begin{abstract}
Sites of Memory of the Dictatorship and the process of patrimonialising the political experience
\end{abstract}

\begin{abstract}
:
Places of memory are being institutionalized in places occupied in the past by public institutions marked by the violence and the secret surrounding their activities. In the region of Bico do Papagaio, in the city of Marabá (PA) it is located the Casa Azul, where the National Road's Department (DNER) worked in the 1970's and the 1980's, covering up its real function, because in practice the place worked as a clandestine center of torture. In Xambioá, north of Goiás state, now Tocantins state, several combats occurred in the same period. This article aims to analyze the events that took place in this site in the occasion of the episode known as Araguaia Guerrilla. This is a strategy of memory to appropriate, patrimonialization, musealization and turning into museums these spaces to promote the publicity of the facts covered up by the grey area of the State violence practiced during the Dictatorship of 1964.
\end{abstract}

\section{KEYWORDS:}

cultural heritage; places of memory; Casa Azul; Araguaia Guerrilla; transitional justice.

I Professora Titular do Departamento de História da UNIRIO, do PPGH e do PPGB. Membro da Comissão de Altos Estudos Memórias Reveladas (AN/MJ). Pesquisadora do CNPq.

2 Mestre em Memória Social (PPGMS/UNIRIO) e Doutoranda em História Política e Bens Culturais (PPHPBC-FGV). Bolsista de doutorado FAPERJ, vinculada ao Projeto de Pesquisa Arqueologia da reconciliação: formulação, aplicação e recepção de políticas públicas relativas à violação de direitos humanos durante a ditadura militar, que tem como finalidade gerar subsídios aos trabalhos desenvolvidos pela Comissão Estadual da Verdade do Rio de Janeiro (CEV-RIO). 
« Le devenir de la mémoire est un devenir du savoir fait d'expérience, récits, lectures : le savoir nouveau permet d'expliciter l'insu de l'obscure mémoire. ॥

Gérard Namer

\section{I.Introdução}

A noção de patrimônio nos remete a um juízo de valor, atribuído a objetos, áreas geográficas, cidades, edificações e outros bens culturais. Nascido do vocabulário romano Patrimonium, ganha conotação jurídica e frequentemente assinala um direito adquirido por laços de família, herança do pai, representação da pátria, testemunho do passado, memória. A nova dimensão do termo, que apareceu há cerca de dois séculos, conforme assinala André Chastel (1997: 1433), é global e vaga ao mesmo tempo.

A proposta deste artigo é discutir o processo de reconstrução da memória coletiva tendo como foco um espaço que serviu de palco para episódios dramáticos ocorridos na Floresta Amazônica, na região do Bico do Papagaio, cidade de Marabá, conhecidos como Guerrilha do Araguaia.

Entre as premissas que estão na base do presente artigo, encontram-se algumas ideias e conceitos norteadores das discussões sobre patrimônio, valores e lugares de memória. Trata-se de destacar o contexto das discussões que serão aqui desenvolvidas, assim como a situação de nosso objeto no campo da experiência. Isso nos permitirá recolocar o tema em um quadro social da memória - espaço-tempo, no sentido articulado por Maurice Halbwachs e por seu estudioso e crítico maior, Gérard Namer, em diálogo com Pierre Nora que detém a paternidade do termo "lugares de memória". Seria possível uma articulação de ideias em torno de um acontecimento histórico atualizado pela memória coletiva? Em que medida um conceito se atualiza, no tempo histórico, e pode funcionar como operador do pensamento, conforme assinalado por Gilles Deleuze e Félix Guattari?

A Guerrilha do Araguaia constitui um dos eventos mais emblemáticos e obscuros de nossa história recente. Ocorridos na região do Bico do Papagaio, no norte de Goiás (atual Tocantins), a oeste do Maranhão e no sul do Pará, entre 1972 e 1974, os diversos episódios que ali tiveram lugar são ainda hoje objeto de inúmeras questões não esclarecidas pela historiografia, sobretudo no que se refere aos desaparecimentos dos guerrilheiros que ali tombaram. No contexto histórico marcado pelos 50 anos do golpe que instituiu a Ditadura no Brasil contribuir para os estudos sobre lugares de memória da ditadura pode constituir também uma oportunidade para a atualização das discussões sobre o deslocamento de conceitos no espaço-tempo do conhecimento científico DELEUZE; GUATTARI: 1992) .

Discutiremos questões que se colocam no espírito da Justiça de Transição ${ }^{3}$ e do eixo contido no Plano Nacional de Direitos Humanos (PNDH-3), da

3 "A Justiça Transicional é um ramo altamente complexo de estudo, que reúne profissionais das mais variadas áreas, passando pelo Direito, Ciência Política, Sociologia e História, entre outras, com vistas a verificar quais processos de justiça foram levados a cabo pelo conjunto dos poderes dos Estados nacionais, pela sociedade civil e por organismos internacionais para que, após o Estado de Exceção, a normalidade democrática pudesse se consolidar." (ABRÃO et alii, 2009). 
Secretaria de Direitos Humanos da Presidência da República, aprovado pelo Decreto $n^{\circ} 7.037$, de 21 de dezembro de 2009, cujo Eixo Orientador VI aborda o Direito à Memória e à Verdade. Não por acaso esse é o objetivo maior de diversos segmentos da sociedade e dos movimentos sociais, especialmente dos familiares de mortos e desaparecidos políticos, em busca ainda do reconhecimento dos crimes de Estado cometidos na Ditadura de 1964 no Brasil. Esse Plano constitui um documento bastante avançado em seus objetivos e deveria ser mais claramente conhecido da sociedade brasileira, carente de políticas públicas de direitos humanos e de ações traduzidas em práticas sociais ${ }^{4}$.

Apesar dos acontecimentos terem sido fartamente documentados pelas forças armadas, segundo informações constantes de diversas fontes ${ }^{5}$, os arquivos relativos a esse acontecimento ainda não se encontram inteiramente localizados e/ou recolhidos a alguma instituição arquivística e disponíveis para consulta, como seria esperado, se considerarmos que 30 anos se passaram após o final dos governos militares. Durante mais de 40 anos se negou a existência desses arquivos, muitos dos quais hoje já conhecidos. A prática de documentar sistematicamente as ações empreendidas por agentes do Estado em períodos de exceção se confirma, da mesma forma fica evidente que boa parte da produção documental com valor de prova e peso jurídico jamais chegou ao seu destino, vale dizer, o Arquivo Nacional ou os arquivos estaduais.

Em julho de 200I, o Ministério Público Federal e a CEMDP estiveram na região, em missão de investigação realizada nas cidades de Marabá, São Domingos do Araguaia, Palestina, Brejo Grande, São Geraldo e Xambioá, conforme explica Janaína Teles, membro da referida Comissão e participante da viagem. Presa aos cinco anos de idade com sua família no DOI-CODI de São Paulo, em 1972 , relata em obra que organizou a partir de um seminário realizado em 1997, na USP, que "o Ministério Público colheu cinquenta depoimentos de moradores" (TELES, 200I: 17) das cidades antes mencionadas, o que denota a existência de uma memória viva que sobreviveu ao tempo. A violência utilizada pelas Forças Armadas entre os anos de 1972 e 1974 marcou definitivamente a região e a vida dos moradores. Janaína Teles, sobrinha de André Grabois, desaparecido na Guerrilha do Araguaia, em 1973, explica o alcance dos danos sofridos:

Quase a totalidade da população masculina foi presa e torturada, muitos perderam suas terras e criação de animais e, até hoje [200I], não receberam nenhuma reparação material ou moral em função dos danos sofridos. [...] Os primeiros a serem presos durante essa fase da Guerrilha foram os comerciantes das cidades, depois, os moradores mais afastados dos vilarejos. A população também passou fome, pois as árvores frutíferas e parte da floresta foram destruídas pelos militares e madeireiras. (TELES, 200I: 17)

Em suas investigações na região de Marabá, segundo relata a autora, o Ministério Público

[...] descobriu o escritório do Exército, onde encontrou documentos secretos amplamente divulgados na imprensa. [...] Depois da divulgação

4 Disponível em: <www.sedh.gov.br>. Acesso em: 04 set. 2014.

5 MORAES; SILVA (2005); MORAES (2008); NOSSA (20I2); CAMPOS FILHO (20I2); CAMPOS FILHO (20I5), entre outros. 
dos documentos encontrados em Marabá, o Exército instaurou um Inquérito Policial Militar para apurar possíveis irregularidades cometidas pelo grupo de procuradores que tentam encontrar os restos mortais dos guerrilheiros. A Advocacia Geral da União também fez um pedido para investigar os procuradores. (TELES, 200I: 20)

Décadas se passaram desde que se iniciaram as buscas por informações, documentos, vestígios. Contudo, apesar dos avanços alcançados, os lugares marcados pelos acontecimentos traumáticos do período guardam memórias e histórias em grande medida desconhecidas, o que alimenta um conjunto de representações distorcidas que circulam em veículos de comunicação massiva sobre a história recente do Brasil. Daí a decisão de analisar a literatura interdisciplinar, assim como documentos primários produzidos sobre o tema, como notícias publicadas em jornais, ao longo do tempo, além do Relatório final da Comissão Nacional da Verdade, entre outras fontes. A discussão sobre a natureza dos documentos produzidos em regimes de exceção é imprescindível para a compreensão do trabalho da memória realizado no âmbito da justiça de transição, o que colocará em evidência o testemunho e a experiência não apenas dos que participaram nos episódios aqui analisados e sobreviveram aos mesmos, mas dos juristas e pesquisadores integrantes da Comissão Nacional da Verdade. Afinal, conforme a compreensão de Paul Ricoeur,"com o testemunho inaugura-se um processo epistemológico que parte da memória declarada, passa pelo arquivo e pelos documentos e termina na prova documental" (2007: I70).

O cruzamento dos documentos sensíveis ${ }^{6}$ com os testemunhos colhidos ao longo do tempo abriu caminho para os esclarecimentos necessários à configuração da verdade e ao reconhecimento dos fatos ocorridos, sem os quais não há inscrição na história nem na memória coletiva nacional. Nesse caso, permaneceria o conhecimento fragmentário e distorcido que circula nas instâncias do senso comum, cujo imaginário é formado e reforçado por representações sociais comprometidas com os mesmos episódios. Daí a importância de se distinguirem fatos e representações (PORTELLI, 1996).

Partimos do pressuposto de que o tema aqui tratado diz respeito não apenas aos campos da Museologia, da História, da Arquivologia e da Memória social, mas ao do Direito e, sobretudo, ao da Ciência da Informação que reconhece as fronteiras interdisciplinares desses campos por terem a informação e o documento como parte de suas respectivas problemáticas. $O$ tema enfocado neste artigo situa-se exatamente nesses limites epistemológicos, na medida em que recolhemos de cada campo as diferenças e semelhanças de abordagem dos lugares de memória enquanto expressões de um passado revisitado.

\section{Lugares de Memória, lugares de experiência e as batalhas da me- mória}

O tema da experiência é recorrente nas temáticas abordadas na obra de Walter Benjamin. O narrador, texto clássico da década de 1930, o coloca no centro das discussões quase como um lamento, uma ode à narração como transmissão de experiências, que estaria perdendo espaço para a informação, 
sobretudo aquela que se confunde com notícia e já vem interpretada na origem. Aponta para as perdas trazidas no pós-guerra que impediam as pessoas de contar suas experiências dolorosas, caladas pela dor. Em Experiência e Pobreza, texto originalmente escrito em 1933, Benjamin pergunta: "Na verdade, de que nos serve toda a cultura ${ }^{7}$ se não houver uma experiência que nos ligue a ela?" (BENJAMIN, 20I 2: 86).Antevendo as "atrocidades em massa do século XX" (RICOEUR, 2007: 170), Benjamin denuncia as mídias que valorizam o instantâneo em detrimento da arte de narrar, o que levaria, por via de consequência, à perda da memória do ofício (BENJAMIN, 20I2).

Os lugares de memória são objeto de novas discussões em nossa contemporaneidade e ganham força no âmbito da chamada justiça transicional. Isto porque acontecimentos não revelados em sua inteireza por instituições do Estado passam a ser problematizados por narrativas de personagens que vivenciaram experiências vinculadas a determinados espaços utilizados como centros de tortura durante a Ditadura de 1964. Esclarecimentos das circunstâncias através das quais se deram tais episódios são fundamentais para que as evidências venham à tona e o silêncio se quebre num trabalho de reconhecimento dos crimes então cometidos.

Outrora configurados como lugares privilegiados da tradição e das nações, as linhas que os definiram ainda permanecem vivas em nosso trabalho contemporâneo de reaproximação conceitual.Vejamos a assertiva do autor:

Os lugares de memória nascem e vivem do sentimento [de] que não há memória espontânea, que é preciso criar arquivos, que é preciso manter aniversários, organizar celebrações, pronunciar elogios fúnebres, notariar atas, porque essas operações não são naturais [...].[Os lugares de memória] são bastiões sobre os quais se escoram. Mas, se o que eles defendem não estivesse ameaçado, não se teria, tampouco, a necessidade de construí-los. (NORA, 1993: 13)

A Comissão de Anistia do Ministério da Justiça, instalada em 28 de agosto de 200I, a partir da Medida Provisória $\mathrm{n}^{\circ} 2.15 \mathrm{I}$, tem tido papel fundamental para acolher e promover iniciativas de memorialização. Ao alargar o conceito de reparação para além do ressarcimento monetário, tem promovido ações para cumprir com um dever de cunho moral em relação ao passivo da ditadura, que se ancora no plano simbólico e na perspectiva de promover um debate público sobre o assunto. Para Paulo Abrão (ABRÃO;TORELLY, 20I I), presidente da Comissão, apesar do processo de indenização constituir o eixo estrutural da justiça de transição no Brasil, a partir do artigo 8o do Ato das Disposições Constitucionais Transitórias houve o reconhecimento da anistia aos perseguidos políticos, do direito de resistir, da ideia de anistia ligada à reparação (com variedade de medidas e dirigida aos perseguidos políticos), e sua extensão no tempo e em seu alcance - 1946-1988. O processo de reparação deu visibilidade às lutas das vítimas, grupos ganharam capacidade de ação, o que impulsionou outros movimentos de direitos humanos.

A reparação como reconhecimento mostra que as vítimas não foram só

7 Em outra edição, em vez de "cultura" o tradutor usou a expressão "patrimônio cultural”.Ver BENJAMIN,Walter. Experiência e pobreza. In:__. Magia e técnica, arte e política: ensaios sobre literatura e história da cultura. São Paulo: Brasiliense, 1985, p.I I5. (Obras Escolhidas, I) 
despojadas de suas posses materiais, mas também sofreram perdas no plano subjetivo. Para a recuperação da confiança cívica, a Comissão da Anistia promove as Caravanas da Anistia, a construção do Memorial da Anistia e o projeto Marcas da Memória. As Caravanas da Anistia consistem em sessões públicas itinerantes para pedidos de reparação por perseguição política, quando são realizadas homenagens e atividades culturais e educativas. Ao final das sessões, a palavra é dada ao anistiado, seguido de um pedido de perdão público oficial do Estado, diante do qual a reparação moral e individual ganha âmbito coletivo. Esse ato público transforma a concessão do pagamento em algo secundário, pois os anistiados recuperam seu sentimento de pertencimento ao país, recompondo suas identidades e o próprio sentido de comunidade política. No âmbito coletivo, os atos públicos e homenagens permitem que as novas gerações se sintam inseridas na pluralidade de histórias do país.

A construção do Memorial da Anistia nasceu da necessidade de disponibilizar o acervo dos processos levados a cabo pela Comissão da Anistia, totalizando quase 74.000 processos, contendo documentos escritos, testemunhos, materiais de áudio e vídeo. Estes documentos mostram a perseguição política sofrida pelas vítimas e relatam a história do Brasil na perspectiva dos perseguidos pelo Estado. A partir de grande influência de um processo de memorialização, a materialização desse espaço público de reparação coletiva funcionará como um pedido de perdão do Estado e reconhecimento do direito à resistência e preservação da memória das vítimas.

O projeto Marcas da Memória, por seu turno, tem como objetivo financiar a coleta de testemunhos e práticas de memória executadas e elaboradas por grupos da sociedade civil. As ações do projeto se dividem em quatro campos: (I) Audiências públicas (escuta pública dos perseguidos políticos sobre o passado); (2) História oral (entrevistas com quem viveu a resistência, realizadas pelas universidades UFPE/UFRGS/UFRJ, e que serão disponibilizadas no Memorial da Anistia e nos acervos das respectivas universidades); (3) Convocatórias públicas (seleção de projetos para preservação da memória a partir de editais públicos, e divulgação de iniciativas de memória que surgem de organizações da sociedade civil); e (4) Publicações (memórias de perseguidos políticos, dissertações e teses sobre a ditadura e a anistia, reimpressão de obras e registro de atas de eventos). Tais iniciativas têm o intuito de conhecer melhor o passado através de uma reflexão crítica e de melhorar as instituições democráticas, evitando uma visão única do passado.

As experiências das transições argentina e chilena também são paralelos importantes para pensar o processo de institucionalização desses lugares de memória. Por terem instaurado comissões da verdade logo após suas respectivas aberturas políticas, incorporaram em seus informes a identificação de locais relacionados à prática de crimes contra os direitos humanos durante regimes de exceção.A identificação e publicidade desta geografia da repressão impulsionaram a disputa pela memória destes locais por parte de grupos organizados da sociedade civil, quase sempre representados pelas vítimas e familiares de mortos e desaparecidos, assim como iniciativas do próprio Estado, como medida de reparação simbólica e de promoção de valores que fortaleçam a conscientização em relação aos direitos humanos. 
Nesse sentido, destacamos importantes processos de memorialização no Chile, como o centro clandestino de detenção, tortura e extermínio da ditadura de Pinochet (1973-1990), hoje ressignificado e concebido como o Parque por la Paz Villa Grimaldi8; e o Museo de la Memoria y de los Derechos Humanos9, projeto concebido pelo primeiro mandato presidencial de Michelle Bachelet (2006-20 I0), que se destaca como o museu mais visitado de Santiago. Na Argentina, o complexo da antiga Escuela de la Mecánica de la Armada (ESMA), formado por diversas edificações utilizadas pela Marinha argentina, funcionou como centro de detenção durante a ditadura militar (1976-1983), sendo um dos locais principais de práticas sistemáticas de tortura e assassinatos de opositores ao regime. Tombado durante o mandato do presidente Néstor Kirchner, o complexo foi concebido como Espacio Memoria y Derechos Humanos I0, um lugar de memória de múltiplas ações e de referência no desenvolvimento de reflexões acerca da temática das políticas de memória argentina.

As discussões sobre o patrimônio são de natureza política e traduzem "o problema da consciência coletiva face às ameaças, mais ou menos precisas, mais ou menos obscuras, à sua integridade" (CANCLINI, I995: I26). Na medida em que resulta de uma operação de seleção, combinação e encenação, expressão do antropólogo argentino Néstor Canclini, o patrimônio nacional é legitimado por grupos hegemônicos, que definem o que deve ou não ser preservado. Em seu processo de institucionalização, as ações patrimonialistas ritualizam, repetem e renovam os valores que instituem. $E$ aqui o patrimônio está definitivamente vinculado ao poder instituído. As relações entre patrimônio e memória se estreitam à medida que compreendemos o quanto ambos se determinam e são seletivos em suas práticas. Elegemos sempre aquilo que consideramos digno de integrar nossos acervos, nossas coleções, nosso ideário, nosso panteão cívico, enfim, nossos bens culturais. Nesse processo, promovemos também o esquecimento de tudo aquilo que, por uma razão ou por outra, foge aos nossos critérios de relevância.

O argumento justificador dos novos lugares de memória considera os processos de institucionalização, articulando-se em inúmeros embates com as cadeias da tradição. Lembremos que o reenquadramento da memória institucional passa necessariamente por processos de negociação e de justificação (POLLAK, 1989). Aqui não se encontra mais em jogo apenas a inscrição da experiência vivida na memória coletiva, mas a própria memória coletiva nacional agora colocada em cheque ao atualizarmos o conhecimento sobre o passado. A informação desempenha um papel crucial, pois trabalha com as bases do conhecimento - aqui incluído o novo - realimentando a pesquisa documental e histórica. Os documentos, arquivos, testemunhos, lugares, vestígios, rastros compõem também os sítios de memória e consciência, agora não mais encobertos pela clandestinidade e pelo silêncio. Ao contrário, propõe-se uma educação para a memória, exposta aos olhares da sociedade. Longo e conflituoso caminho a ser pavimentado palmo a palmo! Valores sociais e políticos entram nessa equação complexa e devem por isso ser explicados e compreendidos em sua inteireza.

8 http://villagrimaldi.cl/

9 http://www.museodelamemoria.cl/

10 http://www.espaciomemoria.ar/ 
Em sua "agenda de questões", visando propor uma revisão de premissas relativas ao trabalho no campo do patrimônio cultural, Meneses discute a interação entre práticas e representações, que devem ser mobilizadas pela sociedade, e explica que "atuar no campo do patrimônio cultural é se defrontar, antes de mais nada, com a problemática do valor, que ecoa em qualquer esfera do campo" (MENESES, 2012: 32). No fio da sua argumentação, elenca

[...] os principais componentes do valor cultural:valores cognitivos, formais, afetivos, pragmáticos e éticos. [...] vale acentuar que tais componentes não existem isolados, agrupam-se de forma variada, produzindo combinações, recombinações, superposições, hierarquias diversas, transformações, conflitos. (MENESES, 20I2: 35)

Embora estejamos analisando e discutindo a institucionalização de lugares de memória, parece haver uma aproximação com as ideias destacadas pelo autor, no que se refere à qualificação dos valores citados. Valores cognitivos, por exemplo, poderiam dialogar com a presente reflexão, uma vez que nesse caso o bem "está sendo tratado, então, como documento, ao qual se dirigem questões para obter, como resposta, informação de múltipla natureza" (MENESES, 20 I2: 35). Trata-se, no caso, de trazer para o plano das ideias a produção de informações sobre os episódios relativos à Guerrilha do Araguaia, na perspectiva da memória e da identidade, valores que o autor classifica de afetivos e envolvem "mecanismos complexos, como as representações sociais e o imaginário social" (MENESES, 20I2: 36).

Os lugares de memória da Ditadura, pouco conhecidos da sociedade, não poderiam se impor como patrimônio cultural. Suscitam, por essa razão, um trabalho de articulação entre a história e a memória social que levaria à aceitação e convencimento dos diferentes grupos envolvidos nos respectivos episódios, com seus conflitos, disputas e contradições. Para que exerçam plenamente seu papel social, os lugares mencionados cumpririam a principal função dos museus, vale dizer, a produção de conhecimento.A diversidade de ideias - sejam elas políticas, culturais, sociais - define a categoria dos valores éticos que Meneses associa "não aos bens, mas às interações sociais em que eles são apropriados e postos a funcionar, tendo como referência o lugar do outro” (MENESES, 20 I2: 37).

$\mathrm{Na}$ prática, certamente há fortes tensões e barreiras contendo o avanço dessas iniciativas. A história recente ainda não produziu os efeitos esperados, por força de inúmeros fatores que ainda interferem na comunicação dos saberes produzidos sobre a Ditadura. Será preciso a persistência e o alargamento dos processos de institucionalização do conhecimento que, como assinalado por Michel Foucault, é sempre fruto de uma batalha (FOUCAULT, 1996).

O caso Gomes Lund e outros versus Estado Brasileiro e a condenação do Brasil na sentença exarada pela Corte Interamericana de Direitos Humanos $(\mathrm{CIDH})$ da OEA (24.1 I.20I0) são reveladores dos aspectos mais complexos das lutas políticas em processo de verificação da verdade. Essa condenação impulsionou diversas ações relativas ao Direito à Memória e à Verdade. Cecília Santos, em seu estudo sobre o tema, destaca a implantação do $3^{\circ}$ Programa Nacional de Direitos Humanos, já citado anteriormente, lançado em dezembro de 2009 pela Secretaria Especial de Direitos Humanos da Presidência da República (SEDH), que elegeu o direito à memória e à verdade como um dos seus principais eixos 
norteadores, “o que veio a acirrar divisões já existentes entre alguns setores do governo”. De um lado estaria a SEDH e o Ministério da Justiça, ambos a favor das investigações do passado e contra a aplicação da Lei da Anistia (1979) aos crimes de tortura; e por outro, a Advocacia Geral da União e o Ministério da Defesa, ambos a favor do esquecimento (SANTOS, 20 I0: 125).

Com o tema da justiça de transição no centro da agenda política da SEDH e do Ministério da Justiça, a autora abre o debate sobre medidas e o papel da justiça de transição no Brasil, partindo do pressuposto de que a literatura sobre a transição homogeneíza a atuação do Estado, ignorando ações civis e a mobilização de grupos em prol dos direitos humanos. Nesse sentido, Santos faz um estudo de caso das denúncias de tortura e desaparecimentos encaminhadas à Comissão Nacional dos Direitos Humanos a partir de 1969 - em especial os casos de Olavo Hansen" e da Guerrilha do Araguaia - evidenciando que a crescente globalização do paradigma de "justiça de transição" desempenha pressão política importante para a formulação de novas políticas públicas de reparação. As denúncias analisadas foram importantes para a mobilização jurídica em escalas nacional e transnacional, buscando, para além da reparação civil, a reconstrução da memória e da verdade das violações ocorridas durante o regime militar (SANTOS, 2010: 132).

No caso da Guerrilha do Araguaia, que teve início em 1966, as forças armadas foram responsáveis pela morte de 59 militantes e 17 moradores locais, e pelo aprisionamento de 13 militantes que sofreram torturas sistemáticas. Desde a década de 1970, os familiares de mortos e desaparecidos protagonizam a luta pela recuperação dos corpos de seus entes queridos. Em 1982, este agrupamento impetra uma ação extraordinária contra a União, exigindo a localização e trasladação dos corpos, o esclarecimento das circunstâncias das mortes e o acesso a informações das Forças Armadas. Entre idas e vindas do processo ${ }^{12}$, que levou cerca de 25 anos até que o STF executasse sua sentença final condenando o Estado, as organizações representantes dos familiares de mortos e desaparecidos buscaram respaldo internacional. De acordo com Soares e Quinalha (20I I), a condenação do Brasil pela Corte Interamericana de Direitos Humanos, em dezembro de 2010, no caso conhecido como "Guerrilha do Araguaia”, obrigou - Estado brasileiro a investigar e punir os autores de graves violações de direitos humanos durante o regime militar. Nos pontos estabelecidos pela corte também foram incluídas ações como a realização de atos públicos e a busca, sistematização e publicação de toda a informação relativa à Guerrilha e das violações perpetradas pelo Estado na ocasião. Para os autores, a sentença reforçou

[...] a necessidade de que promovam a memória da resistência à ditadura militar, seja pelo resgate e sistematização das diversas formas de manifestação cultural, seja pela gestão de monumentos e locais que

I I O caso do líder sindical Olavo Hansen, ocorrido em 1970, nas dependências do DOPS/SP, é objeto de análise da autora no artigo citado e não será tratado neste trabalho. Segue o padrão repetido inúmeras vezes pelas instituições oficiais que sequestraram, torturaram e mataram inúmeras pessoas no período, alegando posteriormente que as vítimas atentaram contra a própria vida, como nos casos bastante conhecidos de Vladimir Herzog e Manuel Fiel Filho.

I 2 Santos (2010) esmiúça a trajetória do processo tramitado no STF contra a União, expondo a postura de negação do Estado em reconhecer seus crimes, ancorando-se inicialmente na Lei da Anistia (1979) e, posteriormente, na criação da Comissão Especial de Mortos e Desaparecidos (1995), que havia indenizado e declarado como mortos os militantes desaparecidos no Araguaia. 
lembrem as atrocidades do passado e as violações de direitos humanos. (SOARES; QUINALHA, 20I I: 78)

O trabalho da memória e da justiça prossegue em várias frentes. Veremos a seguir ações direcionadas à divulgação de informações necessárias ao estabelecimento de lugares de memória, em busca da patrimonialização e consequente musealização dos espaços que outrora ancoraram a memória das lutas da resistência ao regime de exceção. Os processos de disputa política e legitimação dos lugares de memória da ditadura no Brasil não são homogêneos, tendo em vista o grupo que os reivindica, os contextos políticos em que estão inscritos e as suas próprias condições materiais e espaciais.

Em São Paulo, o Memorial da Resistência, inaugurado em janeiro de 2009, foi pioneiro na busca pela legitimação do espaço. Ocupando parte do primeiro andar do prédio que fora utilizado pelo Departamento de Ordem Política e Social (DEOPS), de 1940 a 1983, refletiu uma grande conquista no âmbito das políticas patrimoniais do Estado de São Paulo. Após 23 anos tramitando no Condephaat, em 1999 foi decretado o tombamento estadual pautado mais pelas características arquitetônicas e fachadistas da edificação, datada de 1914, do que propriamente por seus usos no passado (NEVES: 20I I). Esta disputa pelo uso e concepção museológica do espaço ganhou força com o tombamento, permitindo que o Núcleo Memória - organismo que se instituiu a partir do Fórum Permanente de Mortos e Desaparecidos Políticos do Estado de São Paulo articulasse com a Secretaria de Cultura do Estado de São Paulo, então gestora do espaço, a concepção e construção do Memorial. Para seus idealizadores, a conquista deste lugar de memória superava o caráter de reparação até então realizado pelo Estado, pautado pela indenização econômica e individual, estendendo simbolicamente a reparação a toda a sociedade.

Em Minas Gerais, o convênio entre a Universidade Federal de Minas Gerais e a Comissão de Anistia, assinado em dezembro de 2012, prevê obras no edifício onde funcionava o Teatro Universitário e o antigo edifício que abrigava a Faculdade de Filosofia e Ciências Sociais, conhecido como "Coleginho". A conclusão das obras de restauro e a construção de um prédio anexo de quatro andares para abrigar a administração do Memorial estavam previstas para 2014, ano de descomemoração dos 50 anos do Golpe de 1964. Mesmo ainda não entregue à sociedade, a concepção do Memorial da Anistia reitera o empenho do Estado brasileiro "em compensar os prejuízos causados a milhares de pessoas pelo uso discricionário do poder", reafirmando sua postura de corrigir os erros do passado através de princípios de accountability ${ }^{13}$, que reforçam sua convicção na democracia (MEZAROBBA, 2003: I46). Por outro lado, ao lançar suas fundações a partir de duas edificações tombadas pela esfera municipal, inscreve como bem comum de Belo Horizonte espaços vinculados à trajetória de militância e resistência política do movimento estudantil e da intelectualidade que compu-

13 Mezarobba utiliza a expressão “princípios de accountability” para designar o caráter dos desdobramentos mais recentes do processo de anistia no Brasil. A autora avalia que até 2003 "a trajetória percorrida pelo Estado não deixa dúvidas de que o investimento principal foi feito em justiça administrativa, especialmente aquela forma restauradora, voltada à compensação financeira", não havendo "empenho em buscar a verdade, tampouco punição" (MEZAROBBA, 2003, p.I46). Em nossa avaliação do cenário transicional atual, entendemos as iniciativas de projetos de cunho simbólico capitaneados pela Comissão de Anistia como um esforço de adequação ao PNDH3 (2007), no qual fica definida a política pública de Direito à Memória e à Verdade. 
nha os quadros acadêmicos da Universidade. A medida para a preservação de suas fundações e fachadas modernas de pouco valor estético reiterou o valor histórico destas edificações no plano simbólico da cidade como lugar de memória.

Em Petrópolis, a partir de uma campanha veiculada na internet, iniciou-se o movimento pela desapropriação do antigo centro clandestino de tortura e extermínio da Ditadura, a Casa da Morte, para transformá-la no Centro de Memória,Verdade e Justiça.A possível tomada desta propriedade particular pelo poder público revela uma nova alternativa para os lugares de memória da Ditadura. Primeiro, por esta casa ter sido utilizada clandestinamente pela estrutura da repressão e por ter seus usos revelados a partir da denúncia de sua única sobrevivente, a militante da organização VAR-Palmares, Inês Etienne Romeu, recém-falecida. Preservar esta memória a partir da desapropriação de um espaço privado reforça o interesse público em revelar a verdade e reconhecer os crimes cometidos no local, multiplicando ainda ações pedagógicas e de informação através da preservação da memória coletiva.

\section{A Casa Azul: um futuro lugar de memória?}

A região do Araguaia guarda, desde a década de 1950, memórias de inúmeros conflitos e disputas pela terra que até hoje se repetem (CAMPOS FILHO: 20I2; 20I5), razão pela qual há diversas iniciativas no sentido de revelar essa experiência à sociedade. Uma das formas encontradas para cicatrizar as feridas e impedir novas formas de violência é inscrever esses acontecimentos, no âmbito da justiça transicional, na memória coletiva nacional via lugares de memória.

A Casa Azul, palco de diversos episódios de violações dos direitos humanos do período em foco ${ }^{14}$, está situada no km I da rodovia Transamazônica, em Marabá, no sul do Pará. Nesse local funcionava, na década de 1970, o Departamento Nacional de Estradas de Rodagem (DNER). Hoje é o Departamento Nacional de Infraestrutura de Transportes (DNIT) que desenvolve suas atividades nesse espaço. $\mathrm{Na}$ realidade, tratava-se de um centro clandestino de tortura, pelas mãos do Centro de Informações do Exército (CIE), aliás, como outros tantos existentes à época e hoje conhecidos em todo o país. $O$ uso de diversas instalações oficiais de instituições do Estado para a prática de tortura, morte e desaparecimentos chamou a atenção da Comissão Nacional da Verdade, que mapeou, em seu relatório final, 23 I locais ${ }^{15}$ associados a graves violações de direitos humanos no território nacional, funcionando entre 1964 e 1985. Era preciso documentar tais crimes. Em setembro de 2014 a Comissão promoveu diligências de reconhecimento do local, com a presença de testemunhas das violações de direitos humanos, para levantar e/ou consolidar informações já conhecidas. Estiveram presentes, ainda, representantes da Comissão da Verdade do Pará, assim como da Comissão Especial de Familiares de Mortos e Desaparecidos Políticos (CEMDP).

14 "Estima-se que ali foram mortos por tortura ou execução mais de trinta guerrilheiros, militantes do PCdoB e moradores acusados de apoiar a Guerrilha." (COMISSÃO NACIONAL DA VERDADE, 20I4. Disponível em: < http://www.cnv.gov.br/images/pdf/relatorio/volume_I_digital.pdf>.Acesso em: 08 jun. 20I5)

I5 Estes locais foram identificados como unidades militares e policiais, estruturas clandestinas e navios-prisões, distribuídos por região: centro-oeste, 8; nordeste, 47; norte, 28; sudeste, 90 ; e sul, 58 (COMISSÃO NACIONAL DA VERDADE, 20।4: 727-839). 
Embora ainda não haja uma ação concreta visando à transformação desse espaço onde hoje funciona o DNIT em um lugar de memória dos conflitos, há uma vigilância comemorativa, através de atos simbólicos, como a Caravana da Anistia e as diligências da Comissão Nacional da Verdade, cujo relatório final deu "publicidade" aos crimes. Apesar de não ter tampouco gerado debate público, na justa medida, conforme Heymann (2006: 20), essas ações foram fundamentais para envolver a comunidade de Marabá, profundamente marcada pelos episódios dramáticos ocorridos na Casa Azul, o que pode se tornar uma ação pela apropriação futura desse espaço. É importante destacar a dimensão simbólica desses atos, pois permitem nos anos que virão reparar danos sofridos pelos envolvidos e/ou seus familiares e descendentes, trazendo esses personagens esquecidos para um lugar público de fala. Os camponeses e moradores locais, que foram obrigados a colaborar como "mateiros" para o Exército, após bárbaras sessões de tortura praticadas no local, até recentemente ainda carregavam essa culpa.

O impacto na região, como já assinalado, foi considerável, pois muitas pessoas perderam também seus meios de cultivo e sobrevivência. Além disso, os camponeses que sofreram perseguições e torturas talvez nunca tenham entrado em um programa de reparação por falta de conhecimento sobre seus direitos. $O$ trauma produzido na geração que viveu o evento e nas posteriores é constatado em diversos relatos, indicando que essas pessoas nunca se recuperaram das marcas do passado, vagando como "loucos" pela comunidade. Por outro lado, é fácil perceber que, diferentemente das outras iniciativas antes mencionadas, mais direcionadas e estruturadas com vistas a patrimonializar e musealizar esse espaço, a Casa Azul desponta nos relatos de antigos moradores como uma memória viva, com forte potencial para tornar-se um lugar de memória na Floresta Amazônica, em cujas matas conflitos violentos tiveram lugar.

Constituindo uma das seis unidades montadas pelo Centro de Informações do Exército para desarticular a guerrilha rural no município de Marabá, a Comissão Nacional da Verdade destacou a Casa Azul, em seu relatório, por ter sido denunciada como local de tortura e extermínio por diversas testemunhas, entre elas, Pedro Matos do Nascimento e Raimundo de Souza Cruz, camponeses acusados pelo Exército de colaborarem com os militantes do PCdoB. Ambos reconheceram a sala onde foram torturados durante suas respectivas prisões em 1973. Abel Honorato, preso em 1972, na Casa Azul, também relatou os maus tratos sofridos no espaço sob a acusação de ser amigo de Oswaldão, militante procurado pelo Exército na região. No caso de Abel, a liberação após as sessões de tortura não significou o fim de sua perseguição. Obrigado a atuar como "mateiro", espécie de guia da região, ficaria sob o comando do major Curió até a década de 1980.

Disseram pra mim: "Você vai agora voltar e vai ter que dar conta dos seus companheiros". [...] Fui obrigado a trabalhar de guia até depois da guerra, sob os olhos de Curió o coronel Sebastião Alves (sic) [Rodrigues] de Moura. Até em Serra Pelada [garimpo dirigido por Curió na década de 1980], fiz missões para ele. Tem 40 anos dessa guerra, mas pra mim é um desgosto. Fui muito judiado, fui muito acabado. Até hoje eu não sou ninguém. [...] Eu tive de contar até o que não sabia para escapar. Eu tive que dizer, forçado, que fui um amigo do Oswaldão, mas hoje eu posso dizer, de verdade, que fui amigo dele, pois ele foi amigo da região, ajudou 
muita gente. (COMISSÃO NACIONAL DA VERDADE, 20I4: 796)

O relato de Manuel Messias Guido Ribeiro, ex-soldado do Exército que atuou na Casa Azul entre 1974 e 1980, também revelou os verdadeiros usos do local, assim como o funcionamento e a circulação de informações dentro da instituição. Além de confirmar os espaços internos utilizados para torturar militantes e camponeses - confirmando que todos os soldados que participavam das operações militares na região presenciavam e tinham conhecimento das torturas praticadas no local -, conta que a mesma estrutura era utilizada para torturar os militares que apresentavam uma conduta mais humanizada com os prisioneiros. Já o sargento João Santa Cruz Sacramento, que atuou nas operações na região do Araguaia a partir de 1972, afirmou que o comando dado pelas Forças Armadas era de matar os guerrilheiros ou levá-los com vida diretamente para a Casa Azul, onde seriam interrogados sob tortura e, em muitos casos, assassinados no local.

\section{4 .Considerações finais}

O processo de reenquadramento da memória dos episódios do Araguaia está em curso. Expressão de Henry Rousso (1985), citada por Michael Pollak (1989: 9), aplica-se à análise de memórias coletivas ou memórias enquadradas que, em momentos de crise, tendem a ser modificadas no curso de um lento trabalho de comprovação, negociação e justificação. Nenhuma memória pode ser imposta arbitrariamente. Daí se dizer que as memórias subterrâneas permanecem vivas, a espera das condições de possibilidade de seu afloramento e posterior inscrição na memória coletiva. Por essa razão não podem ser confundidas com o esquecimento. A institucionalização dos saberes passa por um processo de legitimação (THIESEN: 20I3), sem o qual permanece circulando sem a validação que precede sua aceitação social.

Nesse sentido, os lugares de memória da Ditadura são alvo permanente de disputas e conflitos entre os que pregam a inscrição dos episódios do Araguaia na memória coletiva nacional e os que clamam por "virar a página" do passado, sob a justificativa de que a anistia de 1979 perdoou a todos, como vimos. Com o passar do tempo, à medida que diversos projetos direcionados ao campo da memória, da justiça e da verdade se desenvolvem, paralelamente à atuação dos familiares de mortos e desaparecidos políticos, da Comissão de Anistia, dos Grupos Tortura Nunca Mais, entre outros grupos, fragmentos do passado são reconstituídos. Contudo, as condições necessárias à inscrição dos acontecimentos em lugares de memória ainda não se materializaram. Os valores que rondam as ações de patrimonialização, no contexto aqui discutido, refletem uma "matriz de valores", usando expressão de Meneses (20I2), que desconhece o direito à pluralidade das memórias de grupos, organizações, movimentos sociais. O boom ou surto de memória, pontuado por diversos autores, como Andreas Huyssen (2000) e Pierre Nora (2009: 9) sinaliza a força desse "momento da memória". Nora explica que

[...] o que é novo, e isso está relacionado ao terrível infortúnio do século, é a reivindicação de uma verdade que é mais verdadeira do que a verdade da História.A memória é um tipo de justiça. Em outras palavras, a memória lembra e a História esquece. Hoje em dia, a História deve proporcionar 
o conhecimento, mas a memória [lhe] dá o significado (NORA, 2009: 9).

Para além da polarização que permeia as discussões sobre a experiência do período analisado, as nuances surgem à medida que as pesquisas avançam. $A$ memória tem dado significado ao passado, apesar da presença ainda predominante em nossa sociedade de valores conservadores que se impõem ao campo político como verdade. Finalizamos a discussão sobre a institucionalização de lugares de memória fazendo referência à Nostalgia da luz, documentário de Patrício Guzmán, sobre a distância entre o céu e a terra, entre a luz do cosmos e os seres humanos. No Chile, a três mil metros de altura, os astrônomos vindos do mundo inteiro se reúnem no deserto de Atacama para observar as estrelas. Ao mesmo tempo, a secura do solo preserva intactos os restos humanos de múmias, mineiros, indígenas e ossadas dos prisioneiros políticos da ditadura de Pinochet. Enquanto astrônomos buscam a vida extraterrestre, um grupo de muIheres revolve diuturnamente as pedras em busca de vestígios de seus familiares desaparecidos. Guzmán explica:

A memória tem a força da gravidade. Sempre nos atrai. Os que têm memória são capazes de viver no frágil tempo presente. Os que não a têm não vivem em parte alguma. Cada noite, lentamente, impassível, o centro da Galáxia passa por cima de Santiago. (GUZMÁN: 20I0)

Memória, verdade e justiça são personagens conceituais que caminham inseparavelmente na reconstrução do passado, mas dependem da solução de uma equação política e social - como falar de temas sensíveis numa sociedade que ainda não se reconciliou com seu passado?

\section{Referências}

ABRÃO, Paulo et alii. Justiça de transição no Brasil: o papel da comissão de anistia do ministério da justiça. Brasília, Revista Anistia Política e Justiça de Transição, n. I, jan./jun., 2009.

ABRÃO, Paulo; TORELLY, Marcelo D. El programa de reparaciones como eje estructurador de la justicia transicional en Brasil. In: Justicia Transicional: manual para América Latina. Parte IV: Reparaciones y Reformas Institucionales. Brasília: Comisión de Amnistía, Ministerio de Justicia; Nueva York: Centro Internacional para la Justicia Transicional, 20I I, p.477-52I.

ALMEIDA, Priscila Cabral. Direitos Humanos e espaços concretos: paralelos e reflexões acerca da experiência memorial em antigos centros clandestinos no Brasil e no Chile. In: CARRARA, Ozanan Vicente (org.). Direitos Humanos na América Latina. Nova Petrópolis: Nova Harmonia / São Leopoldo; Karywa, 20I5, p.|19I-2I0.

BENJAMIN,Walter. Experiência e pobreza. In: O anjo da história. Org. e trad. de João Barrento. Belo Horizonte:Autêntica Editora, 20I2, p. 85-90.

CAMPOS FILHO, Romualdo Pessoa. Guerrilha do Araguaia: a esquerda em armas. 2. ed. São Paulo: Fundação Maurício Grabois \& Anita Garibaldi, 2012.

. Araguaia: depois da guerrilha, outra guerra - a luta pela terra no Sul do Pará, impregnada pela ideologia da Segurança Nacional (1975-2000). São Paulo: 
Fundação Maurício Grabois / Editora Anita Garibaldi, 2015.

CANCLINI, N. Consumidores e cidadãos: conflitos multiculturais da globalização. Rio de Janeiro: Editora UFRJ, 1995.

CHASTEL, André. La notion de patrimoine. In: NORA, Pierre (org.). Les lieux de mémoire, I. Paris: Gallimard, 1997.

COMISSÃO NACIONAL DA VERDADE. Relatório / Comissão Nacional da Verdade. - Recurso eletrônico. - Brasília: CNV, 20I4. Disponível em: <www.cnv. gov.br>.Acesso em: I5 abr.20I5.

DELEUZE, Gilles; GUATTARI, Felix. $O$ que é Filosofia? Trad. de Bento Prado Jr. e Alberto Alonso Munoz. Rio de Janeiro: Ed.34, 1992.

FOUCAULT, Michel. A verdade e as formas jurídicas. Rio de Janeiro: Nau Ed., 1996.

HEYMANN, Luciana. $O$ “devoir de mémoire” na França contemporânea: entre a memória, história, legislação e direitos. Rio de Janeiro: CPDOC, 2006. $27 f$.

HUYSSEN, Andreas. Seduzidos pela memória. Rio de Janeiro:Aeroplano, 2000.

MENESES, Ulpiano Toledo Bezerra de. O campo do Patrimônio Cultural: uma revisão de premissas. In: IPHAN. I Fórum Nacional do Patrimônio Cultural: Sistema Nacional de Patrimônio Cultural: desafios, estratégias e experiências para uma nova gestão, Ouro Preto/MG, 2009. Brasília: IPHAN, 20I2, p.25-39. (Anais; v.2, t.I). Disponível em : < http://www.iphan.gov.br/baixaFcdAnexo.do?id=4|8|>. Acesso em: 07 set.20l4.

MEZAROBBA, Glenda. Um acerto de contas com o futuro: a anistia e suas consequências - um estudo do caso brasileiro. 2003. 206f. Dissertação - Faculdade de Filosofia, Letras e Ciências Humanas, Universidade de São Paulo, São Paulo. 2003.

MORAES, Taís; SILVA, Eumano. Operação Araguaia: os arquivos secretos da guerrilha. São Paulo: Geração Editorial, 2005.

MORAES, Taís. Sem vestígios: revelações de um agente secreto da ditadura militar brasileira. São Paulo: Geração Editorial, 2008.

NAMER, Gérard. Mémoire et société. Paris: Méridiens Klincksieck, 1987, p. 16.

NEVES, Deborah Regina Leal. O desafio da preservação da memória da ditadura: o patrimônio histórico em questão. In: Anais do XXVI Simpósio Nacional de História.ANPUH, São Paulo, julho 201 I.

NORA, Pierre. Entre a memória e a história: a problemática dos lugares. Proj. História, São Paulo, n. 10, p.7-28, dez. 1993.

. Memória: da liberdade à tirania. Revista MUSAS, n.4, 2009, p.6-10.

NOSSA, Leonencio. Mata!: o major Curió e as guerrilhas no Araguaia. São Paulo: Companhia das Letras, 2012.

NOSTALGIA de la luz. Direção: Patricio Guzmán. [S.I.]: Icarus Films, 2010. 1 DVD (90 min), NTSC, color. 
POLLAK, Michael. Memória, esquecimento, silêncio. Estudos Históricos, Rio de Janeiro, n.3, 1989.

PORTELLI, Alessandro. O massacre de Civitella val de Chianna. In:AMADO, Janaína; FERREIRA, Marieta de Moraes (orgs.). Usos e abusos da História Oral. Rio de Janeiro: Ed. FGV, 1996.

RICOEUR, Paul. A memória, a história, o esquecimento. Trad. de Alain François et alii. Campinas, SP: Editora da UNICAMP, 2007.

ROUSSO, Henry.Vichy, le grand fossé. Vingtième Siècle - Revue d'histoire, n.5, janvier-mars 1985, p.55-80.

SANTOS, Cecília Macdowell. Questões de justiça de transição: a mobilização dos direitos humanos e a memória da ditadura no Brasil. In: Repressão e Memória Política no Contexto Ibero-Brasileiro: estudos sobre Brasil, Guatemala, Moçambique, Peru e Portugal. Brasília: Ministério da Justiça, Comissão da Anistia; Portugal: Universidade de Coimbra, Centro de Estudos Sociais, 2010.

SOARES, Inês Virgínia Prado; QUINALHA, Renan Honório. Lugares de memória no cenário da justiça de transição. In: Revista Internacional de Direito e Cidadania, n. I0, p.75-86, junho/20II.

TELES, Janaína (org.). Mortos e desaparecidos políticos: reparação ou impunidade?. 2. ed. São Paulo: Humanitas/FFLCH/USP, 200I.

THIESEN, Icléia. Memória institucional. João Pessoa: Editora da UFPB, 2013.

(org.). Documentos sensíveis: informação, arquivo e verdade na Ditadura de 1964. Rio de Janeiro: 7Letras, 2014. 34 I p. 